\title{
Tuning the Electrochemical and Photophysical Properties of Osmium Complexes for Application in Photoredox Catalysis
}

\author{
Samantha L. Goldschmida \\ Eva Bednářováa, \# \\ Logan R. Beck ${ }^{a}$, \# \\ Katherine $\mathrm{Xie}^{\mathrm{a}}$ \\ Nicholas E. S. Taya \\ Benjamin D. Ravetz ${ }^{\mathrm{a}}$ \\ Jun Lib \\ Candice L. Joe ${ }^{b}$ \\ Tomislav Rovis*, a \\ a Department of Chemistry, Columbia University, New York, \\ New York 10027, United States \\ ${ }^{b}$ Chemical Process Development, Bristol Myers Squibb, New \\ Brunswick, New Jersey 08903, United States \\ \#These authors contributed equally. \\ tr2504@columbia.edu
}
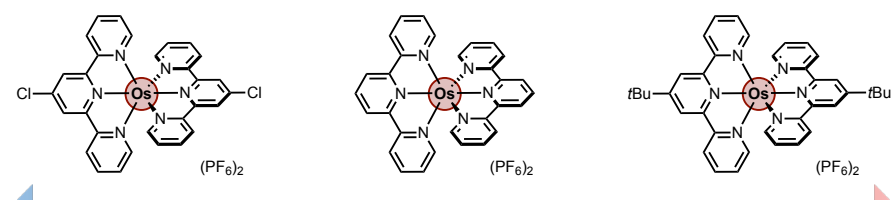

more oxidizing

more reducing
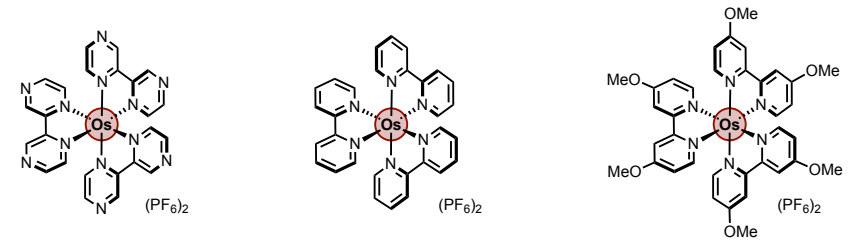

Published online:

DOI:

Abstract Photocatalysis driven by visible and ultraviolet irradiation is a fundamental tool for synthetic chemists. Recently, expansion of this tool to near-infrared (NIR) light has gained in popularity. Herein, we report the detailed photophysical characterization of a library of Os" polypyridyl photosensitizers that absorb NIR irradiation. By tuning ligand scaffold and electron density, we access a range of synthetically useful excited state energies and redox potentials.

Key words photoredox catalysis, near-infrared, ligand design

\section{$1 \quad$ Introduction}

\subsection{Scope}

Photoredox catalysis has emerged as an important tool for synthetic, medicinal, process, and materials chemists alike. ${ }^{1}$ Most state-of-the-art photoredox catalysts today are metal complexes or organic dyes which absorb high energy visible light to generate an excited state capable of acting as a potent single-electron donor, acceptor, or triplet sensitizer. ${ }^{2}$ Recently, our group and others have explored a different modality of photoredox catalysis: one which utilizes lower energy near-infrared (NIR) light to generate these reactive excited states. ${ }^{3,4,5}$

NIR photoredox catalysis is a complementary method to traditional photoredox catalysis in that it offers access to products which may be inaccessible with high energy visiblelight photoredox catalysis. Substrates with extended pisystems or photolabile functionalities may competitively absorb the incident light, which could lead to photocatalyzed substrate decomposition. Additionally, the depth to which NIR light can penetrate various barriers such as biological tissue is greater, allowing for catalysis in vivo. ${ }^{5}$ Finally, photoredox catalysis is generally energetically inefficient, due to the thermal relaxation via intersystem crossing that the excited singlet must undergo in order to reach the catalytically active triplet state. However, due to strong spin-orbit coupling, osmium-based photocatalysts undergo spin-forbidden excitation to directly reach the triplet state upon irradiation with NIR light. Due to the relatively low extinction coefficient of this transition relative to that of the ground state to singlet transition, the incident NIR light can penetrate further into the reaction flask, allowing for photoredox catalysis in batch at mole-scale. ${ }^{4}$ Thus, osmium-complex-catalyzed NIR photoredox catalysis offers energetically efficient catalysis which may be compatible with photo-labile functionalities and could be used in applications on scale and in biological systems.

Polypyridyl complexes of osmium were first synthesized and characterized in the 1940's and 50's, ${ }^{6}$ and have since been studied in various applications including dyesensitized solar cells, ${ }^{7}$ as biological probes, ${ }^{8}$ and binuclear complexes. ${ }^{9}$ Previously, our group developed several osmiumbased photocatalysts and demonstrated their competency at carrying out various transformations with NIR irradiation. ${ }^{4}$ As the ability of these chromophores to achieve reactivity previously only accomplished with near-UV or visible light has now been established, our next goal is to develop a library of catalysts with a wide range of electrochemical properties in order to facilitate the adoption of NIR photoredox catalysis to a broader scope of reactions. Additionally, by identifying the ways in which the electronic structure of the ligands in our library affects the electrochemical and photophysical properties of these complexes, we hope that this manuscript may be used as a guide for future ligand design. 


\section{2} Measuring Ground-State Redox Potentials

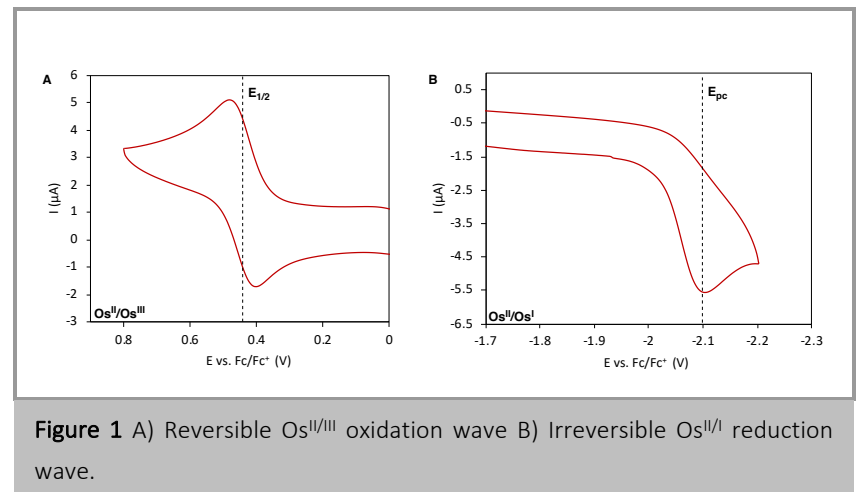

Ground-state redox potentials are measured using cyclic voltammetry (CV). For a reversible redox event, an anodic and cathodic wave are observed, where the standard potential of the reaction is reported as $\mathrm{E}_{1 / 2}$, or halfway between the anodic and cathodic peak currents. At $\mathrm{E}_{1 / 2}$, [ox] $=$ [red] at the electrode surface (Figure 1A).11 For an irreversible redox event, no return wave is observed. Thus, an $\mathrm{E}_{1 / 2}$ value cannot be calculated. In these cases, we take $E_{p c}$ as the value for the formal potential (Figure 1B).

Redox potentials measured in CV must be reported relative to a known reference. While many common aqueous reference electrodes are frequently used to characterize photocatalysts, these are not ideal for measuring accurate redox potentials in organic solvents. ${ }^{13}$ This is due to the junction potential which may arise when the aqueous electrolyte diffuses into the organic solution and vice versa. ${ }^{12}$ The electrochemical data for these experiments were collected in acetonitrile with tetrabutylammonium hexafluorophosphate $\left(\mathrm{TBAPF}_{6}\right)$ as supporting electrolyte. Thus, all redox potentials were referenced to the ferrocene/ferrocenium $\left(\mathrm{Fc} / \mathrm{Fc}^{+}\right)$couple using a pseudo reference electrode and ferrocene as an internal standard.

\subsection{Measuring Photophysical Properties}

Once the ground state redox potentials are determined, the photophysical properties of the chromophore must be measured. The energy of the transitions from the ground state $\left(\mathrm{S}_{0}\right)$ to first excited singlet $\left(\mathrm{S}_{1}\right)$ and ground state to first excited triplet $\left(\mathrm{T}_{1}\right)$ determines the wavelengths of incident light which can be used to excite an electron to these states. Additionally, in order to effectively absorb the incident light and be appreciably promoted to its excited state, the chromophore must have a sufficiently high extinction coefficient at the wavelength of irradiation. In order to probe these properties, UV-visible spectroscopy is employed. As described by the Beer-Lambert Law, the absorbance (A) of a given solution is directly dependent upon the path-length $(\ell)$, the extinction coefficient $(\varepsilon)$, and the concentration (c) of the analyte (Equation 1).

$$
A=\varepsilon c \ell
$$

Thus, by measuring the UV-visible spectrum of each chromophore and using the Beer-Lambert Law to determine their extinction coefficients at various wavelengths, we can determine which wavelengths of light can be used to excite each chromophore and how effectively each chromophore will absorb that light (Figure 2).

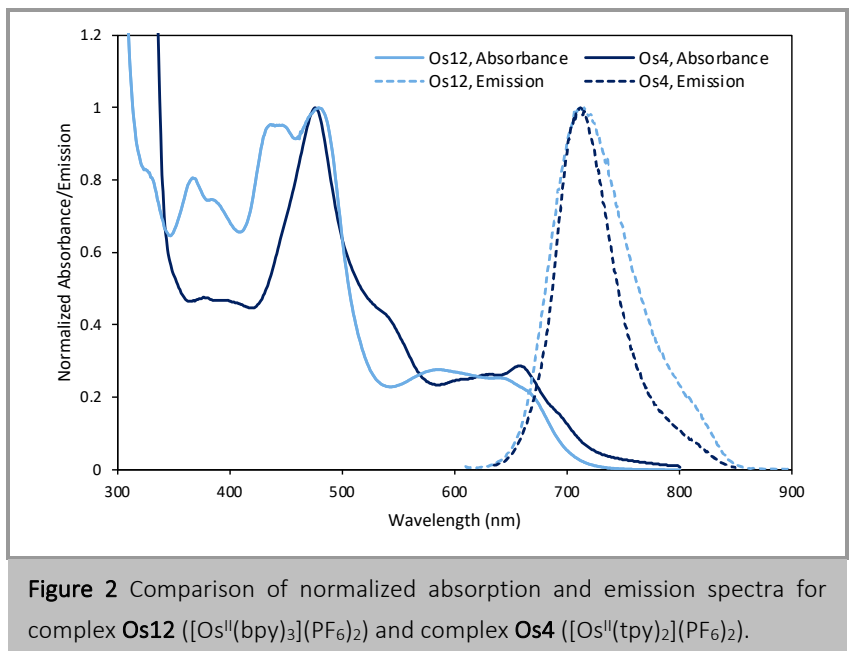

The photophysical properties are also vital for determining the excited-state redox potentials of a photocatalyst. Excited-state redox potentials $\left(E^{*}{ }_{1 / 2}\right)$ are commonly estimated using the Rehm-Weller equation, in which the ground state redox potentials $\left(E_{1 / 2}\right)$ are adjusted using the vibrational zero-point energy ( $\left.\mathrm{E}_{0,0}\right)$ (Equations 2 and 3$) .{ }^{14}$

$$
\begin{aligned}
& \text { (2) } E_{1 / 2}^{* \text { red }}=E_{1 / 2}^{r e d}+E_{0,0}+\omega_{r} \\
& \text { (3) } E_{1 / 2}^{* o x}=E_{1 / 2}^{o x}-E_{0,0}+\omega_{r}
\end{aligned}
$$

Equations 2 and 3 The Rehm-Weller Equation for estimating excited-state reduction (2) and oxidation (3) potentials.

The electrostatic work term $\left(\omega_{\mathrm{r}}\right)$ describes charge separation within the electron-transfer complex and is considered negligible.15 Determining an accurate value for $\mathrm{E}_{0,0}$ is key in estimating these excited-state potentials. Ideally, $\mathrm{E}_{0,0}$ can be determined empirically by measuring the emission spectrum at $77 \mathrm{~K} .{ }^{16}$ If access to this type of instrumentation is not possible, $\mathrm{E}_{0,0}$ is commonly approximated. Many methods to estimate $\mathrm{E}_{0,0}$ have been previously reported, including using A) the wavelength of the emission maximum, ${ }^{17}$ B) the intersection of the normalized absorption and emission spectra, ${ }^{18} \mathrm{C}$ ) the $\mathrm{x}$ intercept at $10 \%$ of the maximum height on the blue-shifted side of the emission spectrum, ${ }^{19}$ and D) the $\mathrm{x}$-intercept of the tangent line drawn at the inflection point of the blue-shifted side of the emission spectrum ${ }^{20}$ (Figure 3 ). We compared these estimation methods with reported $77 \mathrm{~K} \mathrm{E}_{0,0}$ values of known osmium complexes in the literature. Based on this analysis, we have decided to take the lambda max of emission as the best estimate of $\mathrm{E}_{0,0}$ for $\mathrm{OsL}_{3}$-type complexes, while the tangent method is the best fit for OsL2-type complexes. 


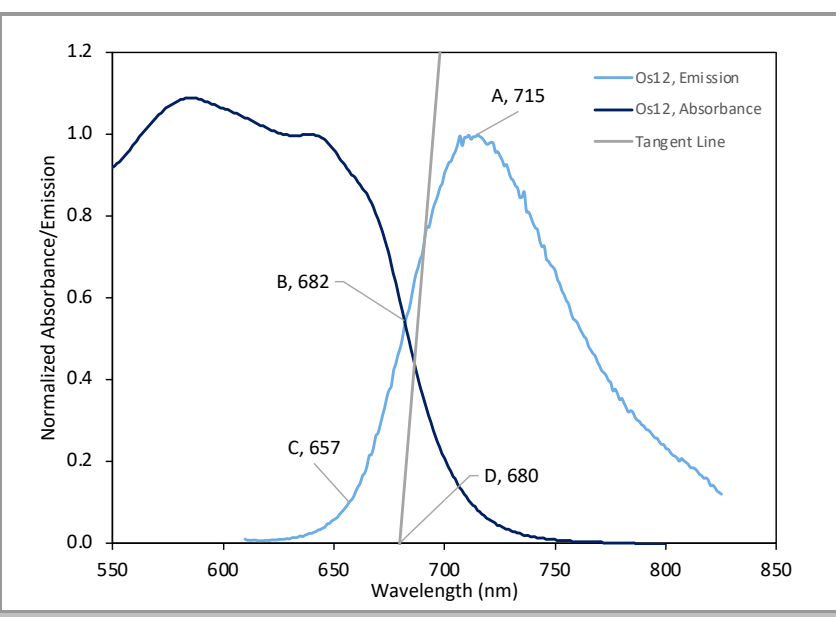

Figure 3 Various methods for approximating the triplet energy of osmium complexes. A) Lambda max of the emission spectrum B) Intersection point of the normalized triplet absorption and triplet emission spectra* C) $10 \%$ of the maximum height of the emission spectrum D) $x$-intercept of the tangent line drawn from the inflection point of the emission spectrum. Measured triplet energy of Os12 from 77K emission spectrum is $708 \mathrm{~nm} .{ }^{21}$ *This method was reported in the literature for singlet absorption and emission spectra.

\subsection{Synthesis of Osmium Complexes}

Two general methods were employed for the synthesis of the osmium complexes reported here (Scheme 1). Complexes Os1-0s19, Os23, 0s24, and 0s25- Os27 were synthesized by Procedure A, using $\mathrm{OsCl}_{3}$ as an osmium source and high temperature $\left(160-230{ }^{\circ} \mathrm{C}\right) .4$ Serendipitously, the diazafluorenone carbonyl of $\mathbf{0 s 2 3}$ was derivatized by the ethylene glycol solvent to form the acetal. Procedure B using $\left(\mathrm{NH}_{4}\right)_{2} \mathrm{OsCl}_{6}$ and milder reaction conditions $\left(130{ }^{\circ} \mathrm{C}\right)$ proved to be more effective for synthesis of complexes 0s20, 0s21, 0s28, and 0s29. All complexes were precipitated as the $\mathrm{PF}_{6}$ salt (except for 0s29 which was isolated as the chloride salt). Recrystallization from acetone with diethyl ether provided pure complexes in most cases. In the case of residual contamination by free ligand, column chromatography could be conducted on neutral alumina to afford the pure complexes.

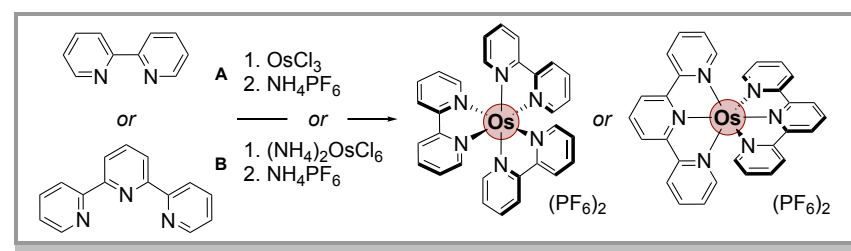

Scheme 1 Procedure A and Procedure B for the synthesis of osmium bipyridyl or terpyridyl complexes.

\section{$2 \quad$ Properties of Osmium Complexes}

Herein, we report standardized electrochemical and photophysical properties of 29 osmium complexes, including six which have not been previously reported. Electrochemical and photophysical data for $\mathrm{OsL}_{2}$ and OsL 3 -type complexes are summarized in Tables 1 and 2, respectively. Their structures are shown in Figures 4 and 5. We observed reversible oxidations and quasi- or irreversible reductions for all complexes.

\subsection{Redox Potentials of OsL2-type Complexes}

This library contains 15 complexes which are derivatives of $\left[\mathrm{Os}(\mathrm{tpy})_{2}{ }^{2+}\right]\left(\mathrm{PF}_{6}\right)_{2}(\mathbf{O s} 4)$. When the terpyridine ligand was substituted in the 4'-position with electron donating substituents (both alkyl groups and electron rich arenes), the metal-centered oxidation from 0 sI $^{\mathrm{II}}$ to $\mathrm{Os}^{\mathrm{III}}$ became more facile. This is evident in the negative shift in ground-state potentials of the Os ${ }^{\mathrm{II} / \mathrm{III}}$ couple. Complexes $0 \mathrm{~s} 9$ (thiophene, $0.49 \mathrm{~V}$, Table 1, Entry 6), Os14 (tert-butyl, 0.46 V, Entry 2), Os15 (4methoxyphenyl, $0.47 \mathrm{~V}$, Entry 7), and 0s17 (2,4,6trimethoxyphenyl, $0.44 \mathrm{~V}$, Entry 8) are all negatively shifted relative to $0 \mathrm{~s} 4(0.57 \mathrm{~V}$, Entry 1). Complex $0 \mathrm{~s} 8$ (furan, $0.52 \mathrm{~V}$, Entry 5) is also negatively shifted, but to a lesser degree. Substituents at the 4'-position which increased the conjugation of the terpyridine ligand, $\mathbf{0 s 6}$ (biphenyl, $0.51 \mathrm{~V}$, Entry 3) and Os7 (naphthyl, $0.52 \mathrm{~V}$, Entry 4), were negatively shifted to about the same degree as 0s8. Complex 0s10, which has both a phenyl group in the 4'-position and methyl groups in the 6and 6"-positions, was also negatively shifted (0.50 V, Entry 9) relative to $\mathbf{0 s 4}$.

Several complexes of osmium and tridentate ligands consisting of electron rich heterocycles were synthesized. The ground state oxidation potential of complex 0s22 (bispyrazole, $0.38 \mathrm{~V}$, Entry 16) was significantly negatively shifted from 0s4, and complex 0s11 (bis-benzimidazole, $0.11 \mathrm{~V}$, Entry 17) had the most negatively shifted OsII/III oxidation potential.

When the terpyridine ligand was substituted in the 4'-position with sigma withdrawing or electron deficient aryl substituents, its oxidation became more difficult. This led to a positive shift in ground state redox potentials. Both functionalizing the terpyridine with an electron withdrawing halogen distally, as in complex 0s3 (4-bromophenyl, $0.59 \mathrm{~V}$, Entry 11), and directly on the 4'-position, as in complex 0s19 (chloride, $0.59 \mathrm{~V}$, Entry 10), positively shifted the oxidation potential to the same extent. Complex $0 \mathrm{~s} 18$ (pyridine, $0.61 \mathrm{~V}$, Entry 12) showed that electron poor heterocycles in the 4'position have a similar effect.

Surprisingly, among all the more electron rich derivatives, only Os22 shows a decrease of ground state reduction potential $(-2.10 \mathrm{~V}$, Entry 16) compared to $\mathbf{0 s 4}$ $(-1.73 \mathrm{~V}$, Entry 1). The reduction potential of complex 0s19 $(-1.55 \mathrm{~V}$, Entry 10) as well as 0s3 (-1.62 V, Entry 11) are significantly positively shifted from 0s4. The reduction potential of $0 \mathbf{3} 3$ is in the same range as complexes whose ligands are substituted with electron neutral arenes, 0s6 (-1.62 V, Entry 3) and 0s7 (-1.63 V, Entry 4), which confirmed the observed phenomenon that distal substitution has only marginal effect on redox potential. Following the same trend, complex 0 s18 shows a ground state reduction at $-1.53 \mathrm{~V}$ (Entry 12).

Various tridentate ligands with electron poor pyrimidine scaffolds were synthesized. Three bis-pyrimidinyl analogs of Os4 were developed with functionalization by an electron rich 


\begin{tabular}{|c|c|c|c|c|c|c|c|c|c|}
\hline Entry & Complex & $E_{1 / 2}\left(O s^{111 / 11}\right)(V)$ & $E_{p}\left(O s^{11 / 1}\right)(V)$ & $\mathrm{T}_{1}(\mathrm{eV})^{\mathrm{b}}$ & $E_{1 / 2}^{*}\left(O s^{111 / 11 *}\right)(V)$ & $\mathrm{E}_{\mathrm{p}}^{*}\left(\mathrm{O} \mathrm{s}^{11^{*} / 1}\right)(\mathrm{V})$ & $\begin{array}{l}\text { Echem HOMO- } \\
\text { LUMO Gap (V) }\end{array}$ & $\lambda_{\text {em }}(e V)$ & $\lambda_{\mathrm{abs}} / \mathrm{nm}\left(\varepsilon^{*} 10^{-3} / \mathrm{M}^{-1} \mathrm{~cm}^{-1}\right)$ \\
\hline 1 & Os4 & 0.57 & -1.73 & 1.81 & -1.24 & 0.08 & 2.3 & 1.74 & $\begin{array}{c}279(44.0), 311(52.3), 476(10.6), \\
539(4.5), 601(2.6), 628(2.8), 660 \\
(3.0)\end{array}$ \\
\hline 2 & Os14 & 0.46 & -1.72 & 1.80 & -1.34 & 0.08 & 2.18 & 1.73 & $\begin{array}{c}311(67.6), 481(17.1), 600(4.5) \\
626(4.6), 656(4.6)\end{array}$ \\
\hline 3 & Os6 & 0.51 & -1.62 & 1.76 & -1.25 & 0.14 & 2.13 & 1.68 & $\begin{array}{c}316(87.8), 492(36.7), 614(6.6) \\
642(7.7), 669(9.1)\end{array}$ \\
\hline 4 & Os7 & 0.52 & -1.63 & 1.78 & -1.26 & 0.15 & 2.15 & 1.70 & $\begin{array}{c}316(32.8), 493(14.5), 609(2.7) \\
640(3.2), 665(3.7)\end{array}$ \\
\hline 5 & Os8 & 0.52 & -1.61 & 1.72 & -1.20 & 0.11 & 2.13 & 1.64 & $\begin{array}{c}314(25.2), 498(11.5), 617(2.3) \\
647(2.7), 675(3.1)\end{array}$ \\
\hline 6 & Os9 & 0.49 & -1.64 & 1.75 & -1.26 & 0.11 & 2.13 & 1.65 & $\begin{array}{c}314(70.5), 492(27.8), 614(5.4) \\
643(6.3), 669(7.2)\end{array}$ \\
\hline 7 & Os15 & 0.47 & -1.66 & 1.76 & -1.29 & 0.10 & 2.13 & 1.68 & $\begin{array}{c}314(74.2), 493(28.3), 608(5.3) \\
641(6.3), 669(7.3)\end{array}$ \\
\hline 8 & Os17 & 0.44 & -1.70 & 1.77 & -1.33 & 0.07 & 2.14 & 1.68 & $\begin{array}{c}313(32.5), 492(13.6), 609(2.7) \\
641(3.2), 670(3.7)\end{array}$ \\
\hline 9 & Os10 & 0.50 & -1.62 & 1.73 & -1.23 & 0.11 & 2.12 & 1.65 & $\begin{array}{c}303(18.3), 392(1.5), 499(2.1) \\
653(0.7), 683(0.8), 725(0.6) \\
\end{array}$ \\
\hline 10 & Os19 & 0.59 & -1.55 & 1.79 & -1.20 & 0.24 & 2.14 & 1.71 & $\begin{array}{c}325(21.9), 482(11.2), 606(2.9) \\
638(3.0), 661(3.1) \\
\end{array}$ \\
\hline 11 & Os3 & 0.59 & -1.62 & 1.77 & -1.18 & 0.15 & 2.21 & 1.69 & $\begin{array}{c}283(71.5), 313(52.0), 489(18.1) \\
610(3.3), 639(3.9), 670(4.6)\end{array}$ \\
\hline 12 & Os18 & 0.61 & -1.53 & 1.76 & -1.15 & 0.23 & 2.14 & 1.67 & $\begin{array}{c}492(17.2), 567(5.9), 610(4.1) \\
646(4.1), 671(4.5)\end{array}$ \\
\hline 13 & Os2 & 0.77 & -1.45 & 1.79 & -1.02 & 0.34 & 2.22 & 1.70 & $\begin{array}{c}301(48.7), 348(16.6), 484(25.9) \\
602(5.6), 631(6.0), 658(6.5)\end{array}$ \\
\hline 14 & Os1 & 0.65 & -1.44 & 1.78 & 1.13 & 0.34 & 2.09 & 1.69 & $\begin{array}{c}306(42.3), 332(28.9), 490(19.3) \\
603(5.1), 634(5.1), 660(5.3)\end{array}$ \\
\hline 15 & Os16 & 0.78 & -1.40 & 1.80 & -1.02 & 0.40 & 2.18 & 1.71 & $\begin{array}{c}309(25.6), 349(11.4), 482(15.0) \\
602(3.6), 632(3.6), 658(3.8)\end{array}$ \\
\hline 16 & Os22 & 0.38 & -2.10 & 2.14 & -1.76 & 0.04 & 2.48 & 2.02 & $\begin{array}{c}302(33.2), 387(15.6), 431(6.6) \\
519(3.2)\end{array}$ \\
\hline 17 & Os11 & 0.11 & -1.70 & - & - & - & 1.81 & $-c$ & $\begin{array}{c}290(37.4), 302(35.9), 314(36.3), \\
346(47.0), 359(58.2), 487(16.3), \\
562(6.0), 619(2.4), 778(1.6)\end{array}$ \\
\hline 18 & Os13 & 0.78 & -1.40 & - & - & - & 2.18 & $-c$ & $\begin{array}{c}304(41.6), 339(64.6), 394(15.9) \\
450(9.2), 498(6.3)\end{array}$ \\
\hline
\end{tabular}

a Counterions are $\mathrm{PF}_{6}{ }^{-}$unless otherwise noted. All measurements were taken in $\mathrm{MeCN}$. For electrochemical measurements, all redox potentials are vs. Fc/Fc ${ }^{+}$, electrolyte in all cases is $100 \mathrm{mM} \mathrm{TBAPF}_{6}$, the scan rate is $100 \mathrm{mV} / \mathrm{s}$, and all samples were sparged with $\mathrm{N}_{2} \cdot{ }^{\mathrm{b}} \mathrm{T}_{1}$ is calculated based on the $\mathrm{x}$-intercept of the tangent line drawn from the inflection point of the emission spectrum. ${ }^{c}$ No emission detected upon excitation above $400 \mathrm{~nm}$.

(Os1, 4-methoxylphenyl, $0.65 \mathrm{~V}$, Entry 14), neutral (Os2, phenyl, $0.77 \mathrm{~V}$, Entry 13), and poor (Os16, 3,5bis(trifluoromethyl)phenyl, $0.78 \mathrm{~V}$, Entry 15 ) arene and at the 4-position of the central pyridine ring. While all bispyrimidinyl derivatives show a significant increase in ground state oxidation potential compared to 0s4, which can be attributed to the lower energy of the HOMO, the distal functionalization of the arene at the 4-position does not have a significant impact. When turning to the ease of the ground state reduction, complex $\mathbf{0 s 1}$ (-1.44 V, Entry 14) and complex 0s2 $(-1.45 \mathrm{~V}$, Entry 13) are about the same, whereas complex 0s16 $(-1.40 \mathrm{~V}$, Entry 15$)$ is the easiest to reduce. Additionally, a bisindazole complex, $0 \mathrm{~s} 13$ (0.78 V, $-1.40 \mathrm{~V}$, Entry 18), was synthesized and showed the same ground state redox potentials as 0s16. 


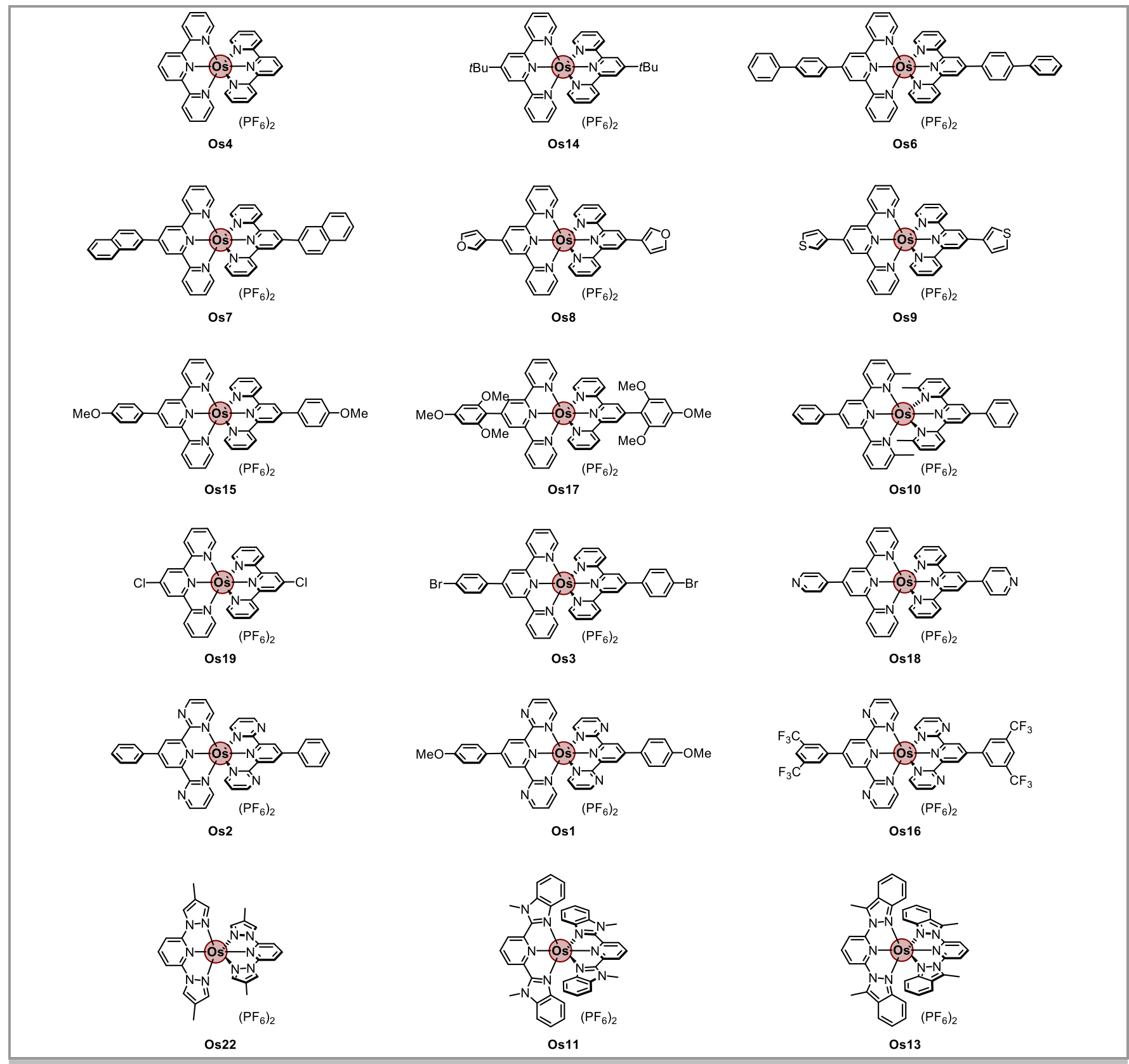

Figure 4 Structures of OsL2-type Complexes

\subsection{Redox Potentials of OsL $\mathrm{L}_{3}$-type Complexes}

The remaining 11 complexes in this library are derivatives of $\left[\mathrm{Os}(\mathrm{bpy})_{3^{2+}}{ }^{2}\left(\mathrm{PF}_{6}\right)_{2}(\mathbf{O s} \mathbf{1 2}\right.$, Table 2, Entry 1) and $\left[\mathrm{Os}(\text { phen })_{3}{ }^{2+}\right]\left(\mathrm{PF}_{6}\right)_{2} \quad$ (Os5, Entry 9), whose ground state oxidations are the same at $0.44 \mathrm{~V}$. A significant decrease of the oxidation potentials by functionalization of the bipyridine scaffold with electron rich groups was shown on complexes Os25, 0s26, 0s27, and 0s28, modified with methyl groups in the 5- and 5'-positions ( $0.38 \mathrm{~V}$, Entry 2), methyl groups in the 4 - and 4'-positions ( $0.35 \mathrm{~V}$, Entry 3$)$, tert-butyl groups in the 4and 4'- positions ( $0.32 \mathrm{~V}$, Entry 4$)$, and methoxy groups in the 4- and 4'- positions (0.07 V, Entry 5) respectively. For the ground state reduction, adding electron donating groups in the 5- and 5'-positions, as in complex 0s25 (-1.87 V, Entry 2), leads to a slightly greater negative shift than adding electron donating groups in the 4- and 4'- positions, as in complexes Os26 (-1.84 V, Entry 3), Os27 (-1.84 V, Entry 4), and 0s28 $(-1.83 \mathrm{~V}$, Entry 5$)$ relative to $\mathbf{0 s 1 2}(-1.68 \mathrm{~V}$, Entry 1$)$.

Modifying the phenanthroline ligand in a similar manner led to an even larger negative shift in potential of the metal-centered oxidation in the case of complex 0s20 $\left(4,4^{\prime}, 5,5^{\prime}\right.$-tetramethyl, $0.19 \mathrm{~V}$, Entry 10) and complex Os21 (5,5'-dimethoxy, $0.01 \mathrm{~V}$, Entry 11). The methyl groups of complex Os20 (-2.02 V, Entry 10) and methoxy groups of complex 0s21 (-2.06 V, Entry 11) both caused a significant negative shift in the potential of the ground state reductions relative to $0 \mathbf{5} 5$ ( $-1.72 \mathrm{~V}$, Entry 9). A bibenzimidazole complex, 0s29 ( $-0.07 \mathrm{~V},-1.82 \mathrm{~V}$, Entry 6$)$, was also synthesized as a more electron rich analog to bipyridine, and its ground state redox potentials were significantly negatively shifted from 0 s12. 
Finally, for electron poor derivatives, a slight positive shift in the ground state redox potentials of $\mathbf{0 s 2 3}$ (diazafluorenone, $0.55 \mathrm{~V},-1.66 \mathrm{~V}$, Entry 7) was observed, while a significant shift was observed for 0s24 (bipyrazine, 1.16 V, -1.05 V, Entry 8).

The difference between the formal potential of the oxidation $\left(\mathrm{E}_{1 / 2}\right)$ and first reduction $\left(\mathrm{E}_{\mathrm{pc}}\right)$ waves, or the electrochemical HOMO-LUMO gap, remained relatively constant across the whole library with an average value $2.14 \mathrm{~V}$ and a standard deviation of $0.14 \mathrm{~V}$.

\subsection{UV-visible Absorption and Emission Spectroscopy}

Both the terpyridyl and bipyridyl osmium complexes studied show sharp, strong absorbance at lower wavelengths, and broad absorbance at higher wavelengths. All complexes except 0s13 and 0s22 can undergo a spin-forbidden direct triplet excitation in the deep-red to NIR 600-700 $\mathrm{nm}$ range. The triplet bands of both $0 \mathbf{8 1 3}$ and $\mathbf{0 s 2 2}$ are significantly blueshifted. Thus, they cannot be excited to $\mathrm{T}_{1}$ via spin-forbidden excitation with NIR light. Orange or green light, however, may be used to achieve this transition. Extinction coefficients of complexes in the range of deep-red and NIR light (600-700 $\mathrm{nm}$ ) are generally in the range of $1.6-7.3 \times 10^{3} \mathrm{M}^{-1} \mathrm{~cm}^{-1}$ for OsL2type complexes and $1.8-4.3 \times 10^{3} \mathrm{M}^{-1} \mathrm{~cm}^{-1}$ for OsL2-type complexes. Our data suggests that as the substituents on the ligand scaffold are changed, the absorption and emission spectra stay relatively constant. Thus, the electronics of the photocatalysts can be freely tuned without negating the ability of the chromophores to undergo spin-forbidden excitation with NIR irradiation. However, complexes 0s11, 0s12, and 0s29, bearing benzimidazole (0s11 and 0s29) or indazole (0s13) heterocycles did not show any emission upon irradiation above $400 \mathrm{~nm}$. Thus, neither their triplet energies, nor their excited state redox potentials could be determined. The non-emissive property of 0s11 was previously described. ${ }^{22}$ Literature DFT calculations for complex $0 \mathbf{1 2}$ attribute the absorbance feature at $586 \mathrm{~nm}$ to the $\mathrm{S}_{0}$ to $\mathrm{T}_{1}$ transition. ${ }^{23}$ The same authors, as well as others, also assigned the major contribution on the HOMO energy to the osmium metal-center, while ligands are the only contributors on the energy of the LUMO in homoleptic complexes. ${ }^{7} \mathrm{~S}_{0}$ to $\mathrm{T}_{1}$ transition can be thus characterized as metal-to-ligand charge transfer.

\begin{tabular}{|c|c|c|c|c|c|c|c|c|c|}
\hline Entry & Complex & $E_{1 / 2}\left(O s^{11 / 1 / 11)}(V)\right.$ & $E_{p}\left(O s^{11 / 1}\right)(V)$ & $\mathrm{T}_{1}(\mathrm{eV})^{\mathrm{b}}$ & $E^{*}{ }_{1 / 2}\left(O s^{11 / 1 / 1 "}\right)(V)$ & $E_{p}^{*}\left(O \|^{1 * / /}\right)(V)$ & $\begin{array}{l}\text { Echem HOMO- } \\
\text { LUMO Gap (V) }\end{array}$ & $\lambda_{\text {em }}(\mathrm{eV})$ & $\lambda_{\mathrm{abs}} / \mathrm{nm}\left(\varepsilon^{*} 10^{-3} / \mathrm{M}^{-1} \mathrm{~cm}^{-1}\right)$ \\
\hline 1 & Os12 & 0.44 & -1.68 & 1.73 & -1.29 & 0.05 & 2.12 & 1.73 & $\begin{array}{c}299(33.6), 325(10.6), 367(10.3) \\
388(9.5), 437(12.2), 447(12.2) \\
479(12.2), 479(12.8), 585(3.5) \\
639(3.3), 667(2.7)\end{array}$ \\
\hline 2 & Os25 & 0.38 & -1.88 & 1.77 & -1.39 & -0.11 & 2.26 & 1.77 & $\begin{array}{c}296(83.9), 374(9.7), 398(9.9), 431 \\
(12.4), 471(13.1), 568(3.5), 629 \\
(3.2)\end{array}$ \\
\hline 3 & Os26 & 0.35 & -1.84 & 1.70 & -1.35 & -0.15 & 2.19 & 1.70 & $\begin{array}{c}291(67.8), 332(13.3), 375(13.7) \\
393(12.6), 443(14.4), 460(14.8) \\
488(15.1), 594(4.4), 657(4.0), 680 \\
(3.3)\end{array}$ \\
\hline 4 & Os27 & 0.32 & -1.85 & 1.71 & -1.39 & -0.14 & 2.17 & 1.71 & $\begin{array}{c}292(83.5), 335 \text { (14.0), } 376 \text { (14.1), } \\
445(15.5), 490 \text { (16.1), } 589 \text { (4.7), } \\
645 \text { (4.3) }\end{array}$ \\
\hline 5 & Os28 & 0.07 & -1.83 & 1.50 & -1.43 & -0.33 & 1.9 & 1.50 & $\begin{array}{c}292(25.6), 341(12.7), 385(12.6) \\
475(11.1), 509(10.5), 618(3.2) \\
688(3.0)\end{array}$ \\
\hline 6 & Os29c & -0.07 & -1.82 & - & - & - & 1.75 & $-d$ & $\begin{array}{c}278(66.8), 343(53.5), 362(48.4) \\
532(11.0), 688(2.2), 759(2.1)\end{array}$ \\
\hline 7 & Os23 & 0.55 & -1.66 & 1.77 & -1.22 & 0.11 & 2.21 & 1.77 & $\begin{array}{c}314(36.4), 380(10.0), 427(12.2) \\
465(13.1), 547(4.6), 625(4.2), 647 \\
(3.6)\end{array}$ \\
\hline 8 & Os24 & 1.16 & -1.05 & 1.83 & -0.67 & 0.78 & 2.21 & 1.83 & $\begin{array}{c}302(14.8), 416(4.4), 469(4.6), 553 \\
(2.3), 612(2.0), 645(1.8)\end{array}$ \\
\hline 9 & Os5 & 0.44 & -1.72 & 1.78 & -1.34 & 0.06 & 2.16 & 1.78 & $\begin{array}{c}290(21.5), 431(17.0), 475(15.2) \\
571(4.9), 630(3.8), 651(3.2) \\
\end{array}$ \\
\hline 10 & Os20 & 0.19 & -2.02 & 1.81 & -1.62 & -0.21 & 2.21 & 1.81 & $\begin{array}{c}300(10.8), 317(3.9), 333(4.6), 434 \\
(14.1), 473(11.8), 559(4.4), 618 \\
(2.8), 646(1.9)\end{array}$ \\
\hline 11 & Os21 & 0.01 & -2.06 & 1.74 & -1.73 & -0.32 & 2.07 & 1.74 & $\begin{array}{c}296(31.0), 307(23.3), 351(7.5), \\
372(8.2), 416(13.8), 443(15.9), \\
463(15.9), 569(5.2), 619(4.2)\end{array}$ \\
\hline
\end{tabular}

a Counterions are $\mathrm{PF}_{6}-$ unless otherwise noted. All measurements were taken in $\mathrm{MeCN}$. For electrochemical measurements, all redox potentials are vs. $\mathrm{Fc}_{\mathrm{F}} \mathrm{FC}^{+}$, electrolyte in all cases is $100 \mathrm{mM} \mathrm{TBAPF}_{6}$, the scan rate is $100 \mathrm{mV} / \mathrm{s}$, and all samples were sparged with $\mathrm{N}_{2} \cdot{ }^{\mathrm{b}} \mathrm{T}_{1}$ is calculated based on the lambda max of emission. ${ }^{\mathrm{c}}$ Counter ions are $\mathrm{Cl}$. ${ }^{\mathrm{d}} \mathrm{No}$ emission detected upon excitation above $400 \mathrm{~nm}$. 


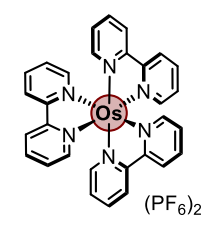

Os12
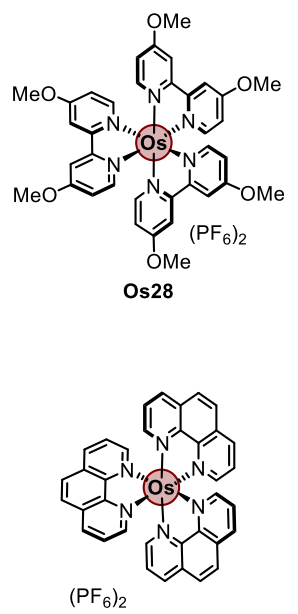

Os5

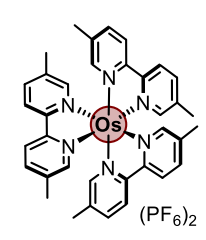

Os25
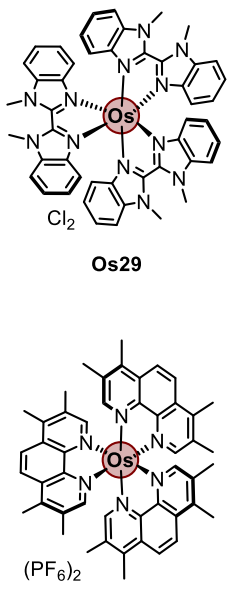

Os20

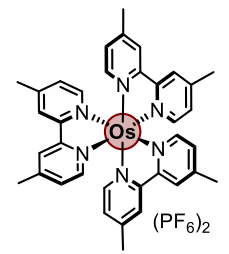

Os26

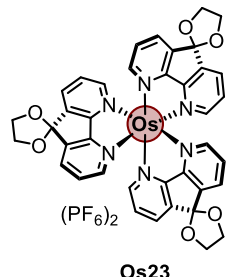

Os23

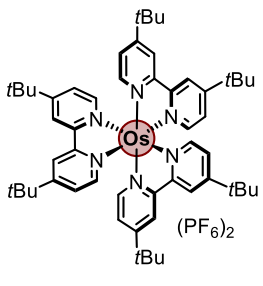

Os27
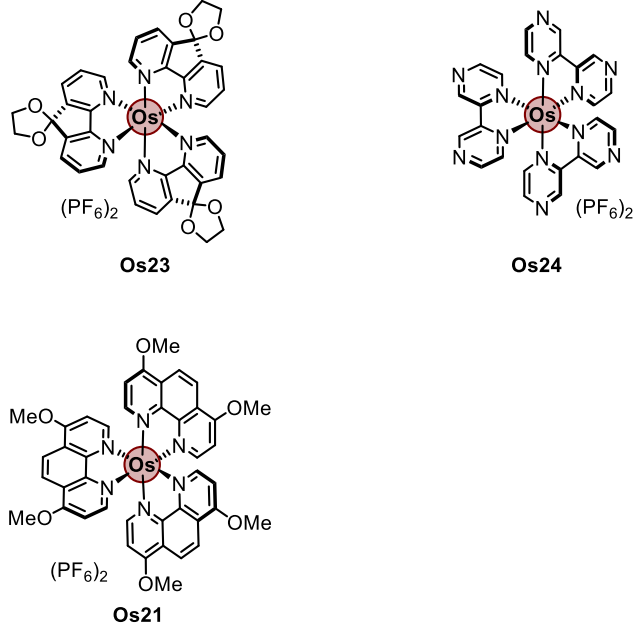

Os21

Figure 5 Structures of OsL 3 -type Complexes

\section{Conclusions}

We have reported the synthesis, standardized characterization, and analysis of a library of new and previously reported Os ${ }^{\text {II }}$ polypyridyl complexes. We generally observed reversible 0 sII/II $^{\mathrm{II}}$ oxidations and quasi-reversible or irreversible reduction waves. The potential of these waves could be modified by tuning the electronics of the ligand scaffolds used. These chromophores have the potential to expand our photocatalytic toolbox to enable broader substrate scope, larger bulk scale, and in vivo therapeutic applications. We hope that the consolidation of these properties here will be a useful resource which makes NIR photoredox catalysis more accessible to the synthetic community.

\section{Funding Information}

Bristol Myers Squibb

\section{Acknowledgment}

EB acknowledges the Experientia Foundation for a postdoctoral fellowship. We are grateful to Bristol Myers Squibb for support.

\section{Supporting Information}

YES.

\section{Primary Data}

NO.

\section{Conflict of Interest}

The authors declare no conflict of interest.

\section{References and Notes}

(1) Romero, N. A.; Nicewicz, D. A. Chem. Rev. 2016, 116, 10075.

(2) Prier, C. K.; Rankic, D. A.; Macmillan, D. W. C. Chem. Rev. 2013, 113, 5322.

(3) Ravetz, B. D.; Pun, A. B.; Churchill, E. M.; Congreve, D. N.; Rovis, T.; Campos, L. M. Nature 2019, 565, 343.

(4) Ravetz, B. D.; Tay, N. E. S.; Joe, C. L.; Sezen-Edmonds, M.; Schmidt, M. A.; Tan, Y.; Janey, J. M.; Eastgate, M. D.; Rovis, T. ACS Cent. Sci. 2020, 6, 2053.

(5) Wang, C.; Zhang, H.; Zhang, T.; Zou, X.; Wang, H.; Rosenberger, J. E.; Vannam, R.; Trout, W. S.; Grimm, J. B.; Lavis, L. D.; Thorpe, C.; Jia, X.; Li, Z.; Fox, J. M. J. Am. Chem. Soc. 2021, 143, 10793.

(6) Thompson, D. W.; Ito, A.; Meyer, T. J. Pure Appl. Chem. 2013, 85, 1257.

(7) van der Westhuizen, D.; Conradie, J.; von Eschwege, K. G. Electroanalysis 2020, 32, 2838.

(8) A, L.; J, A.; J, W. Bioelectrochemistry 2005, 67, 1.

(9) Liu, Y.; De Nicola, A.; Reiff, O.; Ziessel, R.; Schanze, K. S. J. Phys. Chem. A 2003, 107, 3476.

(10) Wang, J. Analytical Electrochemistry; 2nd ed.; John Wiley \& Sons, Ltd: New York, 2000.

(11) Bard, A. J.; Faulkner, L. R. Electrochemical Methods: Fundamentals and Applications; Harris, D.; Swain, E., Eds.; 2nd ed.; John Wiley \& Sons, Ltd: Austin, 2004.

Elgrishi, N.; Rountree, K. J.; McCarthy, B. D.; Rountree, E. S.; Eisenhart, T. T.; Dempsey, J. L. J. Chem. Educ. 2017, 95, 197. Gritzner, G.; Kuta, J. Pure Appl. Chem. 1984, 56, 461.

(16) Riis-Johannessen, T.; Dupont, N.; Canard, G.; Bernardinelli, 
G.; Hauser, A.; Piguet, C. Dalton Trans. 2008, 9226, 3661.

(17) Johnson, S. R.; Westmoreland, T. D.; Caspar, J. V.; Barqawi, K. R.; Meyer, T. J. Inorg. Chem. 1988, 27, 3195.

(18) Wei Xu; Bo Peng; Jun Chen, *; Mao Liang, and; Cai, F. J. Phys. Chem. C 2008, 112, 874.

(19) Till, N. A.; Tian, L.; Dong, Z.; Scholes, G. D.; MacMillan, D. W. C. J. Am. Chem. Soc. 2020, 142, 15830.

(20) Kandoth, N.; Hernández, J. P.; Palomares, E.; Lloret-Fillol, J. Sustain. Energy Fuels 2021, 5, 638.

(21) Ondongo, O. S.; Endicott, J. F. Inorg. Chem. 2009, 48, 2818.

(22) Shao, J. Y.; Zhong, Y. W. Inorg. Chem. 2013, 52, 6464.

(23) Yaxiong Wei; Min Zheng; Lin Chen; Xiaoguo Zhou; Shilin Liu Dalton Trans. 2019, 48, 11763. 